\title{
Description of Two-Metal Biosorption Equilibria by Langmuir-Type Models
}

\author{
K. H. Chong and B. Volesky* \\ Department of Chemical Engineering, McGill University, 3480 University \\ Street, Montreal, Quebec, H3A 2A7, Canada
}

Received November 4, 1994/Accepted March 29, 1995

\begin{abstract}
A biosorbent prepared from Ascophyllum nodosum seaweed biomass, FCAN2, was examined for its sorption capacity. Equilibrium batch sorption studies were performed using two-metal systems containing either $(\mathrm{Cu}+$ $\mathrm{Zn}),(\mathrm{Cu}+\mathrm{Cd})$, or $(\mathrm{Zn}+\mathrm{Cd})$. In the evaluation of the two-metal sorption system performance, simple isotherm curves had to be replaced by three-dimensional sorption isotherm surfaces. In order to describe the isotherm surfaces mathematically, three Langmuir-type models were evaluated. The apparent one-parameter Langmuir constant (b) was used to quantify FCAN2 "affinity" for one metal in the presence of another one. The uptake of $\mathrm{Zn}$ decreased drastically when $\mathrm{Cu}$ or $\mathrm{Cd}$ were present. The uptake of $\mathrm{Cd}$ was much more sensitive to the presence of $\mathrm{Cu}$ than to that of $\mathrm{Zn}$. The presence of $\mathrm{Cd}$ and $\mathrm{Zn}$ alter the "affinity" of FCAN2 for $\mathrm{Cu}$ the least at high $\mathrm{Cu}$ equilibrium concentrations. The mathematical model of the two-metal sorption system enabled quantitative estimation of one-metal (bio)sorption inhibition due to the influence of a second metal. (c) 1995 John Wiley \& Sons, Inc.

Key words: biosorption • cadmium • copper • zinc • twometal systems - Ascophyllum nodosum
\end{abstract}

\section{INTRODUCTION}

The term "biosorption" is used to describe metabolismindependent binding of heavy metals and/or radionuclides to nonliving biomass. The discovery and development of biosorption phenomena provide a basis for a whole new technology aimed at removal of heavy metallic species from dilute solutions in the range of 1 to $100 \mathrm{mg} / \mathrm{L}$. Recovery of some of these metals is a possibility.

The degree of removal of heavy metals from wastewater by biosorption depends on the multimetal competitive interactions in solution with the sorbent material. However, almost all biosorption studies reported so far have been based on one-metal solutions. ${ }^{8,10,19}$ Even when the influence of a second metal is examined, ${ }^{9,14,17,21}$ the results cannot be extrapolated and no predictive conclusions can be drawn.

Moreover, in those two-metal equilibrium batch sorption studies, the effect of the second metal is usually reported based on its starting initial concentration. This is fundamentally inappropriate because the biosorbent is really exposed to the initial concentrations for only a very brief period of

\footnotetext{
* To whom all correspondence should be addressed
}

time. At equilibrium steady state, which is the predominant state of sorption systems examined, the sorbent material is not exposed to the initial concentration but to the final (equilibrium) concentrations of metal ions. This is why the final (equilibrium) concentrations have to be known when equilibrium conditions are dealt with or compared.

To design a cost-effective sorption system, the biosorption capacity of a metal in the presence of other metals has to be quantified. It is inherently more difficult to systematically study the sorption system at equilibrium since there is no control over the resulting equilibrium metal concentrations. Recent attempts ${ }^{5}$ to examine two-metal biosorption systems resulted in three-dimensional plots of sorption isotherm surfaces using true equilibrium concentrations of solute metals. However, the surfaces have not been smoothed and show irregularities which may or may not truly reflect the behavior of the two-metal sorption system. Moreover, the sorption performance of the "virgin" biosorbent studied then was affected by the alginate leached from it ${ }^{4}$ making it difficult to extrapolate the sorption uptake values over the range of the biosorption studies conducted.

This work illustrates a quantitative approach to studying the sorption capacity of a well-stabilized FCAN biosorbent, prepared from the biomass of brown marine alga Ascophyllum nodosum, in conjunction with solutions containing always two of the three metals of interest: $\mathrm{Cd}, \mathrm{Cu}$, and $\mathrm{Zn}$. This is considered a first step in studying multimetal biosorption systems which would more closely represent composition of industrial effluents.

The choice of metals has been made with regard to their industrial use and potential pollution impact. Cadmium, being highly toxic, represents a great potential hazard to humans and the environment particularly since its use is rapidly increasing. Copper is not acutely toxic to humans but its extensive uses and increasing levels in the environment are causes for concern. Zinc is used very extensively by many industries, mainly in galvanizing and in manufacturing brass and other alloys. Zinc is toxic for humans at levels of 100 to $500 \mathrm{mg} /$ day. ${ }^{16}$

\section{MATERIALS AND METHODS}

The biosorbent FCAN2 used was prepared from Ascophyllum nodosum seaweed biomass by crushing and sizing it, crosslinking with formaldehyde, ${ }^{13}$ and washing it with dis- 
tilled water $(3 \mathrm{~h}) .{ }^{4}$ This preconditioning standardized the biosorbent and eliminated subsequent release of its component materials potentially causing some precipitation of the dissolved metal ${ }^{4}$ which tends to interfere with sorption studies. A. nodosum seaweed was selected for its extraordinary ability to sequester $\mathrm{Cu}, \mathrm{Cd}, \mathrm{Zn}$, and other metallic cations from solution. . $^{5,11,13}$ Chemicals used were of analytical grade from Fisher Scientific, USA. The metal solutions were prepared from $\mathrm{Cd}, \mathrm{Cu}(\mathrm{II})$, and $\mathrm{Zn}$ nitrates dissolved in distilled water. Batch equilibrium sorption experiments were carried out using standard batch methodology described elsewhere. ${ }^{5,13,22}$ Metal solutions contained combinations of either $(\mathrm{Cu}+\mathrm{Zn}),(\mathrm{Cu}+\mathrm{Cd})$, or $(\mathrm{Cd}+\mathrm{Zn})$ in the concentration range of 0 to $350 \mathrm{mg} / \mathrm{L}$ of each one of the metals. Adjustment of $\mathrm{pH}$ to 4.5 in small equilibrium sorption batches was done every hour by adding small amounts of diluted $\mathrm{HNO}_{3}$ or $\mathrm{NH}_{4} \mathrm{OH}$ as required. By the end of the third hour of contact, the $\mathrm{pH}$ remained relatively constant at $\mathrm{pH} 4.5( \pm 0.2)$. Due to the unknown effects of buffer compounds on biosorption, buffering was not used.

The final (residual) metal concentration $C_{f}\left[\mathrm{M}_{1}\right]$ and $C_{f}\left[\mathrm{M}_{2}\right]$ in the test solutions were determined by AAS (Thermo Jarrel Ash Model Smith-Hieftje 11), leading to the respective calculated values for biosorbent metal uptakes $q\left[\mathbf{M}_{1}\right]$ and $q\left[\mathbf{M}_{2}\right]$ for the first metal $\left[\mathbf{M}_{1}\right]$ and for the second metal $\left[\mathrm{M}_{2}\right]$ in each biosorption system using the general definition $^{22}$ :

$$
q(\mathrm{mmol} / \mathrm{g})=V\left(C_{i}-C_{f}\right) / m
$$

where $C_{i}$ is the initial metal concentration in solution of volume $V$, and $m$ is the dry mass of biosorbent. Appropriate controls and blanks were examined throughout the sorption experiments to check the glassware sorption of metals and other potential side effects. The seaweed and particularly FCAN derived from it contained no detectable amounts of $\mathrm{Cu}, \mathrm{Cd}$, or $\mathrm{Zn}$ that could influence the sorption results.

\section{RESULTS AND DISCUSSION}

As a basis for the line of investigation considered, conventional one-metal sorption isotherms were experimentally determined for the biosorbent examined in this study. These isotherms, derived at the same $\mathrm{pH}(\mathrm{pH} \mathrm{4.5)}$ and at room temperature, are presented in Figure 1. Depending on the metal ion under consideration, an optimum $\mathrm{pH}$ exists for its biosorptive sequestering. The respective maximum cadmium $^{18}$ and zinc uptakes by formaldehyde crosslinked $A$.

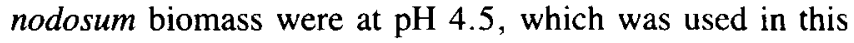
study also to avoid complications due to $\mathrm{Cu}$-hydroxide precipitating at higher $\mathrm{pH}$. The $\mathrm{pH}$ level in the sorption system was maintained constant by addition of either $\mathrm{HNO}_{3}$ or $\mathrm{NH}_{4} \mathrm{OH}$. While hydrogen ions may play an important role in the multicomponent adsorption, only the three heavy metals of interest were followed in this work. Molar concentration units were used which are useful for eventual stoichiometric comparison of the sorption capacity for each of the three metals.

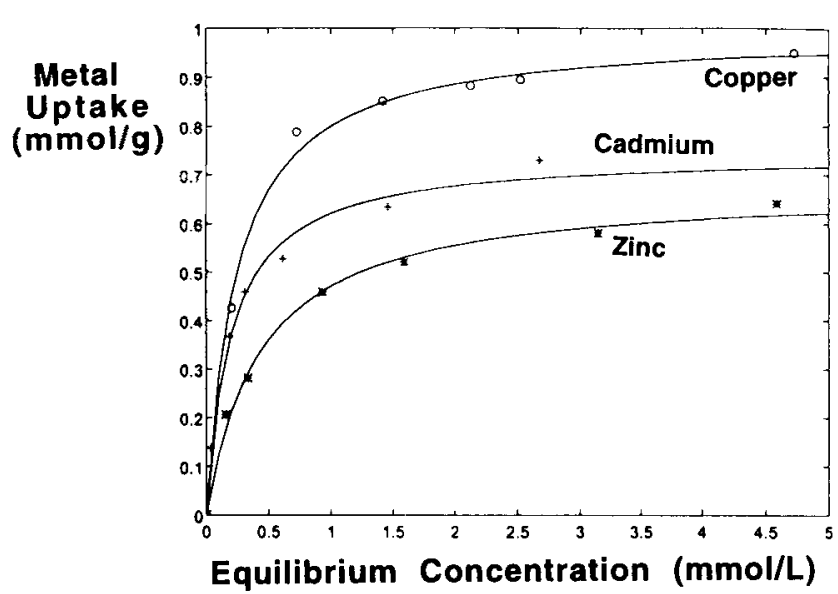

Figure 1. Biosorption isotherms for FCAN 2 and $\mathrm{Cu}(0), \mathrm{Cd}(+)$, and $\mathrm{Zn}\left({ }^{*}\right)$ at $\mathrm{pH} 4.5$ and $22^{\circ}$ to $25^{\circ} \mathrm{C}$.

Biosorption of metals by FCAN can be approximated ${ }^{12.13}$ by a Langmuir-type adsorption isotherm model:

$$
q=\left(\mathbf{b} C_{f} q_{\max }\right) /\left(1+\mathbf{b} C_{f}\right)
$$

where $q_{\max }$ is the maximum sorbate (metal) uptake and $\mathbf{b}$ is the Langmuir constant, a ratio of the adsorption rate constant to the desorption rate constant, which is related to the energy of adsorption through the Arrhenius equation. The apparent dissociation constant for the sorption system $(K)$ is the ratio of the desorption rate constant to the adsorption rate constant and it is the inverse of the Langmuir constant $\mathbf{b}$.

Experimental $C_{f}$ and $q$ data were used to evaluate the constants, $q_{\max }$ and $\mathbf{b}$, according to the least square fitting method. The curves in Figure 1 were generated from Langmuir model equations with the appropriate constants as summarized in Table I.

The most appropriate and correct way of representing the biosorption equilibrium of a two-metal system is to construct a three-dimensional (3-D) sorption isotherm plot whereby the metal uptake is plotted as a function of the final equilibrium concentrations of the two metals. The metal uptake in this case can be either the uptake of one of the metals or the total uptake of both metals. Figures $2 a$ and $2 b$ are examples the copper uptake and the total metal uptake, respectively, for the $(\mathrm{Cu}+\mathrm{Cd})$ solution system.

The computer program, MATLAB (Version 4.0), a highperformance interactive software package for scientific and engineering numeric computation, is capable of plotting a 3-D diagram based on randomly generated experimental data. It can either simply connect the experimental data

Table I. Biosorption parameters for single-metal uptake.

\begin{tabular}{cccc}
\hline Metal & $\begin{array}{c}q_{\max } \\
{[\mathrm{mmol} / \mathrm{g}]}\end{array}$ & b & $K$ \\
\hline $\mathrm{Cu}$ & 0.99 & 4.10 & 0.24 \\
$\mathrm{Cd}$ & 0.75 & 4.98 & 0.20 \\
$\mathrm{Zn}$ & 0.68 & 2.27 & 0.44 \\
\hline
\end{tabular}




\section{Interpolated Surfaces of Cu-Cd System}

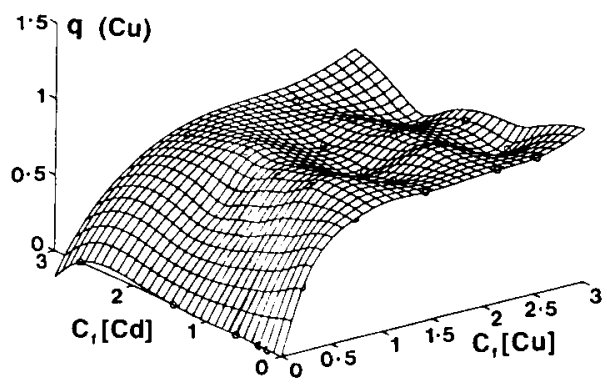

(a)

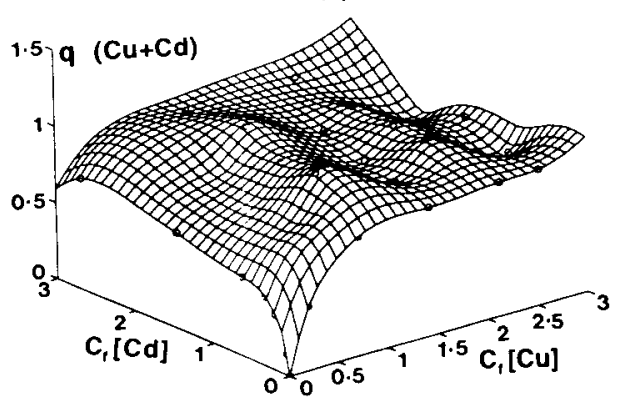

(b)

"Slicing" through the surface in Figure a

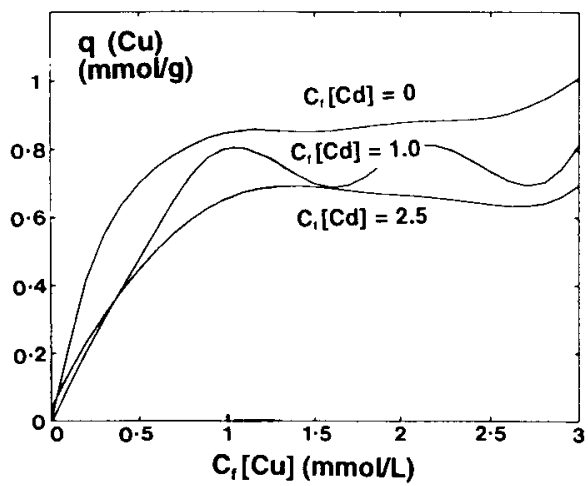

(c)

Figure 2. Interpolated sorption isotherm surfaces for FCAN2 and the two-metal system comprised of $\mathrm{Cu}-\mathrm{Cd}$. Equilibrium contact at $\mathrm{pH} 4.5$ and $22^{\circ}$ to $25^{\circ} \mathrm{C}$. (a) $\mathrm{Cu}$ uptake is plotted as a function of the final equilibrium concentrations of $\mathrm{Cu}$ and $\mathrm{Cd}$. (b) The total uptake of $\mathrm{Cu}$ and $\mathrm{Cd}$ is plotted as a function of the final equilibrium concentrations of $\mathrm{Cu}$ and $\mathrm{Cd}$.

Figure 2. (continued) (c) "Slicing'" through the surface in Figure 2(a) by "iso-concentration" $(x-z)$-planes representing $C_{f}(\mathrm{Cd})$ of $0,1.0$, and 2.5 $\mathrm{mmol} / \mathrm{L}$, respectively.

points by a 3-D mesh through interpolation (Figs. 2a and $2 b)$ or it can fit a smooth surface to the data. The latter approach, which is more desirable, requires the MATLAB user to input an appropriate equation representing the surface.

To obtain two-dimensional (2-D) sorption isotherm curves for one metal at constant final concentration(s) of the other metal, the 3-D sorption isotherm surface can be "cut" by the constant second-metal concentration plane. Figure $2 \mathrm{c}$ represents the outcome of "cutting" through the surface in Figure $2 \mathrm{a}$ by "isoconcentration" $(x-z)$-planes representing $C_{f}(\mathrm{Cd})$ values of $0,1.0$, and $2.5 \mathrm{mmol} / \mathrm{L}$, respectively.
As shown in Figures 2a and b, creating an interpolated surface through the data has its disadvantages. There are lumps and irregularities on the surfaces possibly due to experimental errors associated with those data points in space. At times (Fig. 2a), the surface might even enter beyond the positive axis, thus creating a "negative" uptake. Not having a surface represented by an equation, the (isoconcentration) curves derived from the "cuts" of the 3-D plot have to be smoothed, possibly by using the Langmuir model as described earlier. A major disadvantage of this approach is, however, that there are no real experimental data which are represented by the "cut" curve (such as shown in Fig. 2c) which reflects only the intrapolated surface points. The resulting "wavy" curve may not represent the actual sorption phenomenon and there may be pitfalls in attempts to interpret it. Fitting of the surface to the experimental data points available throughout the 3-D domain results in a more accurate representation of the system behavior and it is superior to the earlier more simplistic attempts. The smoothed surface can be fitted by the most suitable known equation which, in turn, allows further convenient processing of experimental results. Moreover, the use of equations is preferable since the accuracy of mesh surfaces depends on the number of experimental data points available for interpolation.

To propose the most suitable equation to represent the sorption data in a 3-D space, three models were investigated. The first model produced an equation with three parameters, while the second and the third model had four and five parameters, respectively. These parameters, related to each of the two-metal systems studied, were evaluated by minimizing the sum of squared residuals (residual refers to the difference between experimental metal uptake and that predicted from the model). Again, the MATLAB 4.0 program was used for this purpose. The following are descriptions of each of the models together with the equations resulting from the models as well as parameters of the equations representing each two-metal system studied. Notation:

$[B]=$ concentration (number) of unoccupied binding sites.

$\left[B_{o}\right]=$ total concentration (number) of binding sites.

$\mathbf{M}_{1}=$ metal $1 ; \mathbf{M}_{2}=$ metal 2 .

\section{Model 1}

When equilibrium is established:

$$
\begin{array}{ll}
B+\mathrm{M}_{1} \rightleftharpoons B-\mathrm{M}_{1} & K_{1}=k_{-\mathrm{i}} / k_{1} \\
B+\mathrm{M}_{2} \rightleftharpoons B-\mathrm{M}_{2} & K_{2}=k_{-2} / k_{2}
\end{array}
$$

Assume:

$$
d\left[B-\mathrm{M}_{1}\right] / d t=0, d\left[B-\mathrm{M}_{2}\right] / d t=0
$$

(The sorption system is in equilibrium: there are no net changes of $\left[B-\mathbf{M}_{1}\right]$ and $\left[B-\mathbf{M}_{2}\right]$ with respect to time).

$$
\left[B_{o}\right]=[B]+\left[B-\mathrm{M}_{1}\right]+\left[B-\mathrm{M}_{2}\right]
$$


Result:

$$
\left[B-\mathrm{M}_{1}\right]=\frac{\left[B_{o}\right]\left[\mathrm{M}_{1}\right]}{K_{1}+\left[\mathrm{M}_{1}\right]+\left(K_{1} / K_{2}\right)\left[\mathrm{M}_{2}\right]}
$$

We define $\left[B-M_{1}\right]$ as the number of binding sites occupied by $\mathrm{M}_{1}$ per gram of biosorbent, and $\left[B_{o}\right]$ as the total number of binding sites per gram of biosorbent. Then, by multiplying both sides by a value having the units of " $\mathrm{mmol}$ $M_{1}$ per number of binding sites," we obtain:

\begin{tabular}{|c|c|c|c|}
\hline \multicolumn{4}{|c|}{$q\left(\mathbf{M}_{1}\right)=\frac{\left(q_{\max } / K_{1}\right) C_{f}\left[\mathbf{M}_{1}\right]}{1+\left(1 / K_{1}\right) C_{f}\left[\mathbf{M}_{1}\right]+\left(1 / K_{2}\right) C_{f}\left[\mathbf{M}_{2}\right]}$} \\
\hline $\begin{array}{l}\text { Metal } \\
\text { system }\end{array}$ & $\begin{array}{c}K_{1} \\
(\mathrm{mmol} / \mathrm{L})\end{array}$ & $\begin{array}{c}K_{2} \\
(\mathrm{mmol} / \mathrm{L})\end{array}$ & $\underset{(\mathrm{mmol} / \mathrm{g}}{q_{\max }}$ \\
\hline $\mathrm{Zn}-\mathrm{Cd}$ & $\mathrm{Zn}: 0.44$ & Cd: 0.15 & 0.67 \\
\hline $\mathrm{Cu}-\mathrm{Cd}$ & Cu: 0.16 & Cd: 0.53 & 0.98 \\
\hline $\mathrm{Cu}-\mathrm{Zn}$ & Cu: 0.22 & $\mathrm{Zn}: 1.11$ & 0.92 \\
\hline
\end{tabular}

\section{Model 2}

When equilibrium is established:

$$
\begin{aligned}
& B+\mathrm{M}_{1} \quad \rightleftharpoons B-\mathrm{M}_{1} \quad K_{1} \\
& B+\mathrm{M}_{2} \quad \rightleftharpoons B-\mathrm{M}_{2} \quad K_{2} \\
& B-\mathrm{M}_{1}+\mathrm{M}_{2} \rightleftharpoons B-\mathrm{M}_{1}-\mathrm{M}_{2} \quad K_{1.2} \\
& B-\mathrm{M}_{2}+\mathrm{M}_{1} \rightleftharpoons B-\mathrm{M}_{1}-\mathrm{M}_{2} \quad K_{2,1} \\
& B+\mathrm{M}_{1}+\mathrm{M}_{2} \rightleftharpoons B-\mathrm{M}_{1}-\mathrm{M}_{2} \quad K=K_{1} K_{1,2} \\
& =K_{2} K_{2,1}
\end{aligned}
$$

Assume:

$$
\begin{gathered}
d\left[B-\mathrm{M}_{1}\right] / d t=0, \\
d\left[B-\mathrm{M}_{2}\right] / d t=0, \\
d\left[B-\mathrm{M}_{1}-\mathrm{M}_{2}\right] / d t=0
\end{gathered}
$$

\begin{tabular}{|c|c|c|c|c|c|c|}
\hline \multicolumn{7}{|c|}{$q_{\max } C_{f}\left\{\mathbf{M}_{1}\right]\left\{1+\left(K_{1} / K\right) C_{f}\left[\mathbf{M}_{2}\right]\right\}$} \\
\hline $\begin{array}{l}\text { Metal } \\
\text { system }\end{array}$ & $\begin{array}{c}K_{1} \\
(\mathrm{mmol} / \mathrm{L})\end{array}$ & $\begin{array}{c}K_{2} \\
(\mathrm{mmol} / \mathrm{L})\end{array}$ & $\begin{array}{c}K_{1.2} \\
(\mathrm{mmol} / \mathrm{L})\end{array}$ & $\begin{array}{c}K_{2,1} \\
(\mathrm{mmol} / \mathrm{L})\end{array}$ & $\begin{array}{c}K \\
(\mathrm{mmol} / \mathrm{L})^{2}\end{array}$ & $\begin{array}{c}q_{\max } \\
(\mathrm{mmol} / \mathrm{g}\end{array}$ \\
\hline $\mathrm{Zn}-\mathrm{Cd}$ & $\mathrm{Zn}: 0.45$ & Cd: 0.15 & 16.18 & 48.85 & 7.24 & 0.67 \\
\hline $\mathrm{Cu}-\mathrm{Cd}$ & Cu: 0.15 & Cd: 0.58 & 34.02 & 8.98 & 5.20 & 0.99 \\
\hline $\mathrm{Cu}-\mathrm{Zn}$ & $\mathrm{Cu}: 0.22$ & $\mathrm{Zn}: 1.21$ & 46.53 & 8.47 & 10.27 & 0.93 \\
\hline
\end{tabular}

and

$\left[B_{o}\right]=[B]+\left[B-\mathbf{M}_{1}\right]+\left[B-\mathbf{M}_{2}\right]+\left[B-\mathbf{M}_{1}-\mathbf{M}_{2}\right]$

(The sorption system is in equilibrium: there are no net changes of $\left[B-\mathbf{M}_{1}\right],\left[B-\mathbf{M}_{2}\right]$ and $\left[B-\mathbf{M}_{1}-\mathbf{M}_{2}\right]$ with respect to time.)

Result:

$$
\begin{aligned}
& {\left[B-\mathrm{M}_{1}\right]=} \\
& \frac{\left[B_{o}\right]\left[\mathrm{M}_{1}\right]\left\{1+\left(K_{1} / K\right)\left[\mathrm{M}_{2}\right]\right\}}{K_{1}+\left[\mathrm{M}_{1}\right]+\left(K_{1} / K_{2}\right)\left[\mathrm{M}_{2}\right]+2\left(K_{1} / K\right)\left[\mathrm{M}_{1}\right]\left[\mathrm{M}_{2}\right]}
\end{aligned}
$$

By similar procedures as above for Model 1, we obtain:

\section{Model 3}

The following equation is based on the multicomponent sorption isotherm model ${ }^{3,15}$ :

$$
q\left[\mathrm{M}_{1}\right]=\frac{\left(q_{\max } / K_{1}\right) C_{f}\left[\mathrm{M}_{1}\right]}{1+\left(1 / K_{1}\right) C_{f}\left[\mathrm{M}_{1}\right]^{K_{3}}+\left(1 / K_{2}\right) C_{f}\left[\mathrm{M}_{2}\right]^{K_{4}}}
$$

\begin{tabular}{cccccc}
\hline $\begin{array}{c}\text { Metal } \\
\text { system }\end{array}$ & $\begin{array}{c}K_{1} \\
(\mathrm{mmol} / \mathrm{L})\end{array}$ & $\begin{array}{c}K_{2} \\
(\mathrm{mmol} / \mathrm{L})\end{array}$ & \multicolumn{2}{c}{$\begin{array}{c}K_{3} \\
\text { (dimensionless) }\end{array}$} & $\begin{array}{c}K_{4} \\
(\mathrm{mmol} / \mathrm{g})\end{array}$ \\
\hline $\mathrm{Zn}-\mathrm{Cd}$ & $\mathrm{Zn}: 0.30$ & $\mathrm{Cd}: 0.10$ & 0.95 & 0.87 & 0.62 \\
$\mathrm{Cu}-\mathrm{Cd}$ & $\mathrm{Cu}: 0.15$ & $\mathrm{Cd}: 0.51$ & 0.98 & 1.14 & 0.98 \\
$\mathrm{Cu}-\mathrm{Zn}$ & $\mathrm{Cu}: 0.19$ & $\mathrm{Zn:} 0.91$ & 0.97 & 1.13 & 0.91 \\
\hline
\end{tabular}

Relatively little model development has been done for equilibrium binary or multimetal biosorption system. Model 1 presented here resembles that used for describing a competitive inhibition in enzyme kinetics studies. ${ }^{1}$ The result of this model is a binary Langmuir-type equation which has been used in multicomponent biosorption for equilibrium isotherms. ${ }^{20}$ For the $\mathrm{Zn}-\mathrm{Cd}$ system, higher values of the $K$ parameter for $\mathrm{Zn}$ than for $\mathrm{Cd}$ imply that the biosorbent has a higher affinity for $C d$ than for $Z n$. Higher values of $K$ are associated with a higher ratio of the desorption rate constant to the adsorption rate constant. While true quantitative judgment cannot be done, using a similar argument it can also be concluded that the biosorbent has a higher affinity for $\mathrm{Cu}$ than $\mathrm{Cd}$. Note that this could also be concluded from onemetal sorption isotherms.

The second model resembles that describing an uncompetitive inhibition in enzyme kinetics studies. ${ }^{1}$ Similar to the first model, a Langmuir-type equation resulted but there are extra terms in the numerator and the denominator. It can be seen that the values of $K_{1,2}$ and $K_{2,1}$ are generally severalfold higher than those of $K_{1}$ and $K_{2}$. This implies that the formation of the $B-M_{1}-M_{2}$ complex is not as favorable when compared to the $B-\mathrm{M}_{1}$ and $B-\mathrm{M}_{2}$ complexes. Like in Model 1, the $K$ values indicate the preference of the biosorbent according to the order $\mathrm{Cu}>\mathrm{Cd}>\mathrm{Zn}$.

The third equation, derived from the multicomponent isotherm model, is similar to the first equation except that there is a new parameter incorporated as an exponent to each of the residual concentrations in the denominator. The values of $K_{1}$ and $K_{2}$ parameters obtained from this model also lead to similar conclusions as those drawn from Models 1 and 2. $K_{3}$ values are quite close to unity, while $K_{4}$ values deviate from unity by about $\pm 13 \%$. It can be concluded that Model 3 is very similar to Model 1 .

The values of $K$ for the $\mathrm{Cd}-\mathrm{Zn}$ system, derived from Model 1 and Model 2 are quite similar to those obtained from corresponding one-metal systems (Table I). However, this is not the case for $\mathrm{Cu}-\mathrm{Zn}$ and $\mathrm{Cu}-\mathrm{Cd}$ systems. There is a possibility of predicting the two-metal biosorption equilibria from one-metal sorption isotherms depending on the type of metals studied. The presence of $\mathrm{Cu}$ decreases the affinity of FCAN2 for the other two metals as indicated by the higher $K$ values. For example, the value of $K$ for $\mathrm{Cd}$ increased from 0.20 for the one-metal system to 0.53 
(Model 1) and 0.58 (Model 2). Similarly, $K$ for $\mathrm{Zn}$ increased from 0.44 to 1.11 (Model 1) and 1.21 (Model 2).

Table II and Table III show the percentage of calculated data which deviated $10 \%$ (or less) from the experimental metal uptakes and the sum of the squared residuals (SSR) which resulted from applying the three models, respectively. The three models fit the $\mathrm{Cu}-\mathrm{Zn}$ sorption system better than the other two-metal systems examined. Generally, Table II shows that the models can better predict the metal uptake for the system whereby $\mathrm{Cu}$ is favored. For example, in the $\mathrm{Cu}-\mathrm{Zn}$ system, all three models predicted well almost 95\% of the experimental $\mathrm{Cu}$ data as compared with only about $60 \%$ of the $\mathrm{Zn}$ data. However, when the biosorbent has a high affinity for both metals, as in the case of the $\mathrm{Cu}-\mathrm{Cd}$ system, the experimental data of this system deviate the most from the model predictions (the SSR for the $\mathrm{Cu}$ $\mathrm{Cd}$ system are the highest). Deviations from the Langmuirlike model in biosorption studies, especially at low residual concentration, have been reported. ${ }^{2,6}$ However, in this study, the calculated data which deviated more than $10 \%$ are not concentrated in the more sensitive region of low final concentrations.

The largest and the smallest variances are associated with Model 1 and Model 3. In general, the selection criterion for the best model is usually based on the minimum variance. However, because the three models represent the data in a very similar manner, the choice of the best model is reduced to looking for the one with the lowest number of parameters. Because Model 1 has only three parameters, it can be judged as a model which is simpler and it will be further applied in describing the behavior of the three two-metal systems.

Equations from Model 1 can be represented by 3-D (bio)-

Table II. Percentage of calculated data which deviated (0\% to 10\%) from the experimental data.

\begin{tabular}{lccc}
\hline & $\begin{array}{c}\text { Model } 1 \\
{[\%]}\end{array}$ & $\begin{array}{c}\text { Model 2 } \\
{[\%]}\end{array}$ & $\begin{array}{c}\text { Model 3 } \\
{[\%]}\end{array}$ \\
\hline $\mathrm{Cd}$ & 76 & 73.7 & 79.0 \\
& $(32.4)$ & $(29.6)$ & $(33.7)$ \\
$\mathrm{Zn}$ & 50.0 & 50.0 & 47.0 \\
& $(63.3)$ & $(57.7)$ & $(56.2)$ \\
$\mathrm{Cd}+\mathrm{Zn}$ & 79.0 & 81.5 & 86.8 \\
& $(20.9)$ & $(21.6)$ & $(21.4)$ \\
$\mathrm{Cu}$ & 60.5 & 60.5 & 65.8 \\
& $(31.0)$ & $(28.7)$ & $(30.9)$ \\
$\mathrm{Cd}$ & 50.0 & 55.0 & 50.0 \\
& $(73.4)$ & $(51.8)$ & $(69.3)$ \\
$\mathrm{Cu}+\mathrm{Cd}$ & 57.9 & 57.9 & 63.2 \\
& $(43.9)$ & $(51.8)$ & $(31.1)$ \\
$\mathrm{Cu}$ & 94.6 & 94.6 & 94.6 \\
& $(11.9)$ & $(10.7)$ & $(19.8)$ \\
$\mathrm{Zn}$ & 52.6 & 65.8 & 63.1 \\
& $(51.0)$ & $(39.5)$ & $(44.7)$ \\
$\mathrm{Cu}+\mathrm{Zn}$ & 86.8 & 86.8 & 97.4 \\
& $(31.7)$ & $(39.5)$ & $(10.6)$ \\
\hline
\end{tabular}

The maximum percentage deviations of calculated data from experimental data are indicated in parentheses.
Table III. Residual sum of squares. ${ }^{\mathrm{a}}$

\begin{tabular}{cccc}
\hline System & $\begin{array}{c}\text { Degree of } \\
\text { freedom }\end{array}$ & $\begin{array}{c}\text { Sum of square } \\
\text { residuals }\end{array}$ & $\begin{array}{c}\text { Mean } \\
\text { square }\end{array}$ \\
\hline $\mathrm{Zn-Cd}$ & & & \\
Model 1 & 35 & 1027.4 & 29.3 \\
Model 2 & 34 & 1020.3 & 30.0 \\
Model 3 & 33 & 858.6 & 26.0 \\
Cu-Cd & & & \\
Model 1 & 35 & 2341.9 & 66.9 \\
Model 2 & 34 & 2246.1 & 66.0 \\
Model 3 & 33 & 2081.3 & 63.0 \\
Cu-Zn & & 400.0 & 11.7 \\
Model 1 & 34 & 347.6 & 10.5 \\
Model 2 & 33 & 271.5 & 8.5 \\
Model 3 & 32 & & \\
\hline
\end{tabular}

${ }^{\text {a }}$ Residual $=$ difference between experimental metal uptake in miliigrams per liter and that from model prediction.

sorption isotherm surfaces as presented in Figure 3. While these 3-D isotherm surfaces represent the summary of the two-metal equilibrium results, the selected cuts through the 3-D diagrams presented in Figure 4 better reveal the quantitative trends observed in the two-metal sorption systems. Moreover, the effect of the secondary metal presence on the uptake of the primary metal (Fig. 5) can be derived from Figure 4. The curves resulting from the cuts of the 3-D diagrams conform well to the Langmuir model. The Langmuir parameter, $\mathbf{b}$, the ratio of the adsorption rate constant to the desorption rate constant, is an indication of the "apparent affinity" of the biosorbent toward a metal. The Langmuir b value differs for each of the selected cuts of the 3-D sorption isotherm surfaces. It is useful to plot these b values as a function of the equilibrium concentration of a cocation (Fig. 6).

\section{Cu-Cd System}

For a given $C_{f}[\mathrm{Cd}]$, as $C_{f}[\mathrm{Cu}]$ increased, the uptake of $\mathrm{Cu}$ also increased (see Fig. 4a). However, this increase became gradually smaller at higher $\mathrm{Cu}$ concentrations, possibly due to the "saturation" of sites within the biosorbent. The total uptake of metals increased with increasing $C_{f}$ of one metal when the $C_{f}$ of the other metal was held constant. For the case when $C_{f}[\mathrm{Cu}]=2.5 \mathrm{mmol} / \mathrm{L}$ (last segment of Fig. 4a), increasing $C_{f}[\mathrm{Cd}]$ did not alter much the total uptake, whereby it remained quite constant at $0.93 \mathrm{mmol} / \mathrm{g}$, as it gradually approached the limit of $q_{\max }$. Note that Figure 4 is produced from Model 1 whereby the parameter $q_{\max }=$ $0.98 \mathrm{mmol} / \mathrm{g}$.

In general, application of Model 1 indicated that the presence of one metal in the sorption system always lowers the sorption capacity for the other metal, an apparent case of sorption competition. Compared with single-metal sorption, the total amount of metal sequestered by the biosorbent was always higher when the material was exposed to two-metal solutions except for the case mentioned above.

At low final concentrations of cadmium and copper $(0.5$ 

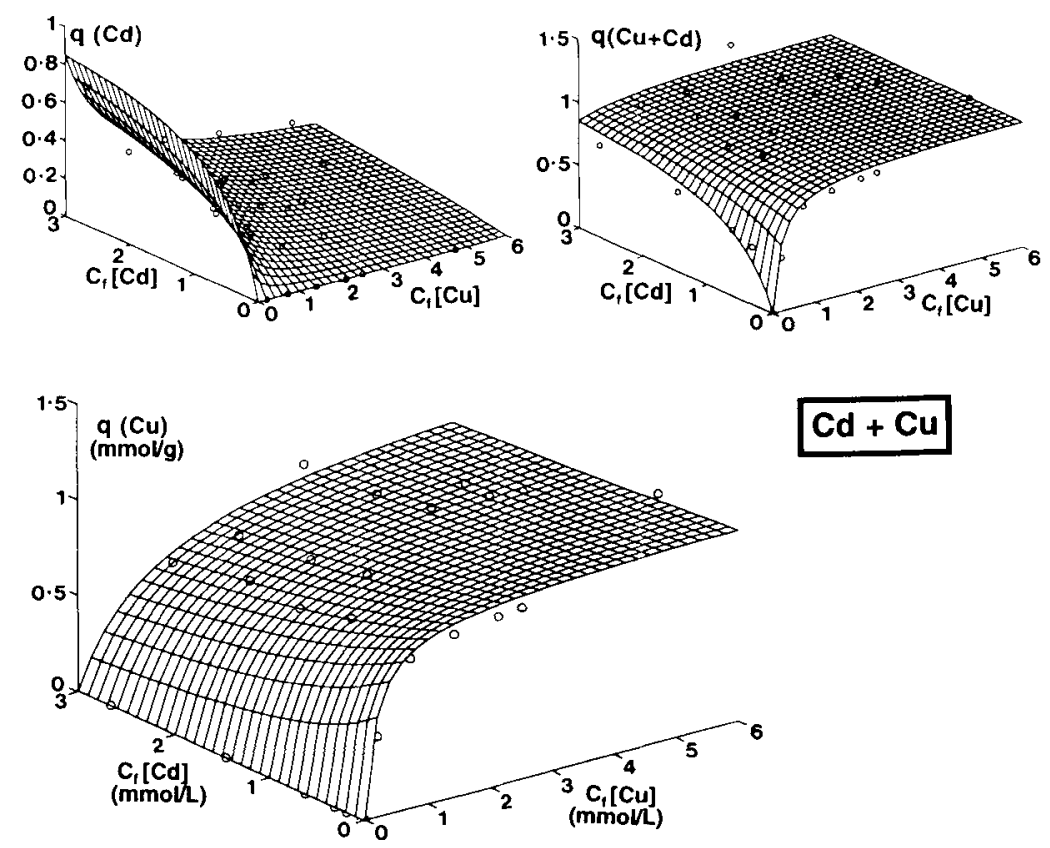

$\mathrm{Cd}+\mathrm{Cu}$

(a)
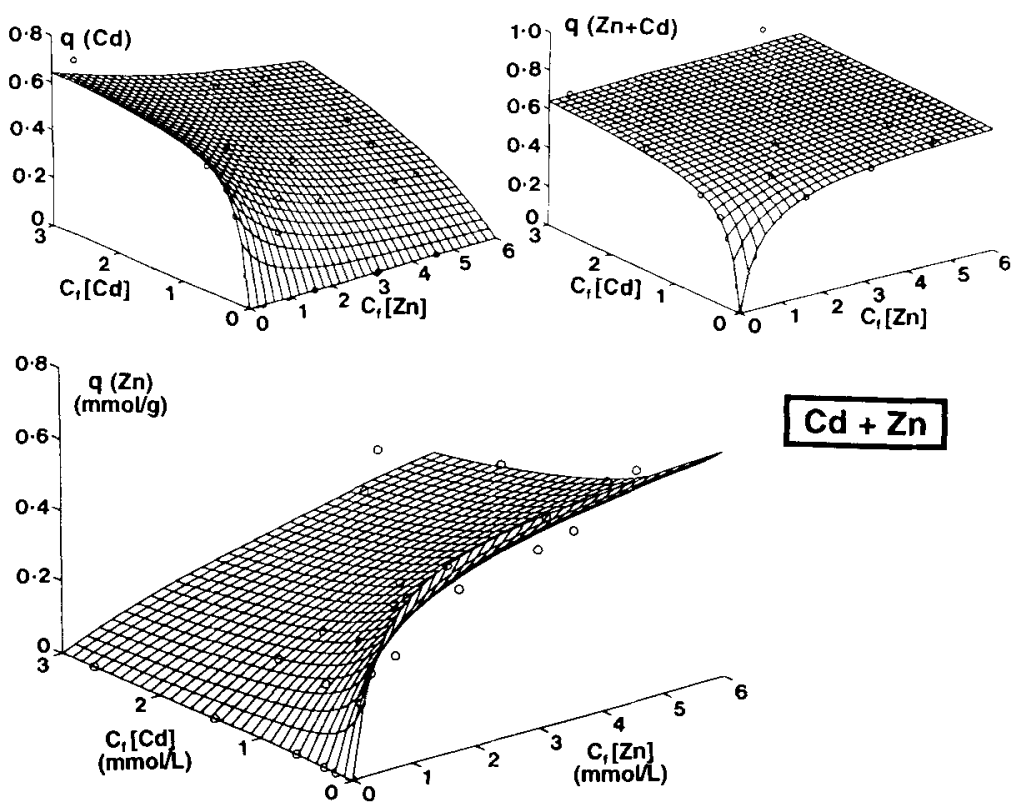

$C d+Z n$

(b)

Figure 3. Two-metal sorption isotherm surfaces for FCAN2 biosorbent. The total and individual metal uptakes are plotted as a function of the final equilibrium concentrations of the two metals. All three possible plots for each two-metal system are presented. Equilibrium contact at $\mathrm{pH} 4.5$ and $22^{\circ}$ to $25^{\circ} \mathrm{C}$. (a) Two-metal system containing ( $\mathrm{Cd}+\mathrm{Cu}$ ) in solution. (b) Two-metal system containing $(\mathrm{Cu}+\mathrm{Zn})$ in solution. (c) Two-metal system containing $(\mathrm{Cd}+\mathrm{Zn})$ in solution.

$\mathrm{mmol} / \mathrm{L}$ of each), FCAN2 demonstrated a preference for sorbing $\mathrm{Cu}$ over $\mathrm{Cd}$, whereby, of the total metal uptake of $0.79 \mathrm{mmol} / \mathrm{g}, 77 \%$ was contributed by the uptake of copper. At high concentrations $(2.5 \mathrm{mmol} / \mathrm{L}$ of each metal $)$, the total metal uptake increased to $0.94 \mathrm{mmol} / \mathrm{g}$, but again $77 \%$ was due to copper uptake. For the case in which each metal would comprise approximately $50 \%$ of the total metal uptake, the residual concentration of cadmium would have to be three or four times greater than that of copper. An example of this case is when $C_{f}[\mathrm{Cu}]=0.5$, while $C_{f}[\mathrm{Cd}]=$ 1.5 or $2 \mathrm{mmol} / \mathrm{L}$. At high concentrations of copper $(2.5$ $\mathrm{mmol} / \mathrm{L}$ ), although the inhibition of $\mathrm{Cu}$ sorption was being compensated by the $\mathrm{Cd}$ uptake, the total uptake remained relatively constant.

Overall, preference of the FCAN2 material for sorbing $\mathrm{Cu}$ over $\mathrm{Cd}$ is apparent over the entire concentration range studied.

\section{Cu-Zn System}

As $C_{f}$ of one of the metals increased, both the total metal uptake and the uptake of that metal increased when the $C_{f}$ of the other metal was held constant (see Fig. 4b). The exception was clearly seen when $C_{f}[\mathrm{Cu}]=2.5 \mathrm{mmol} / \mathrm{L}$ (last 

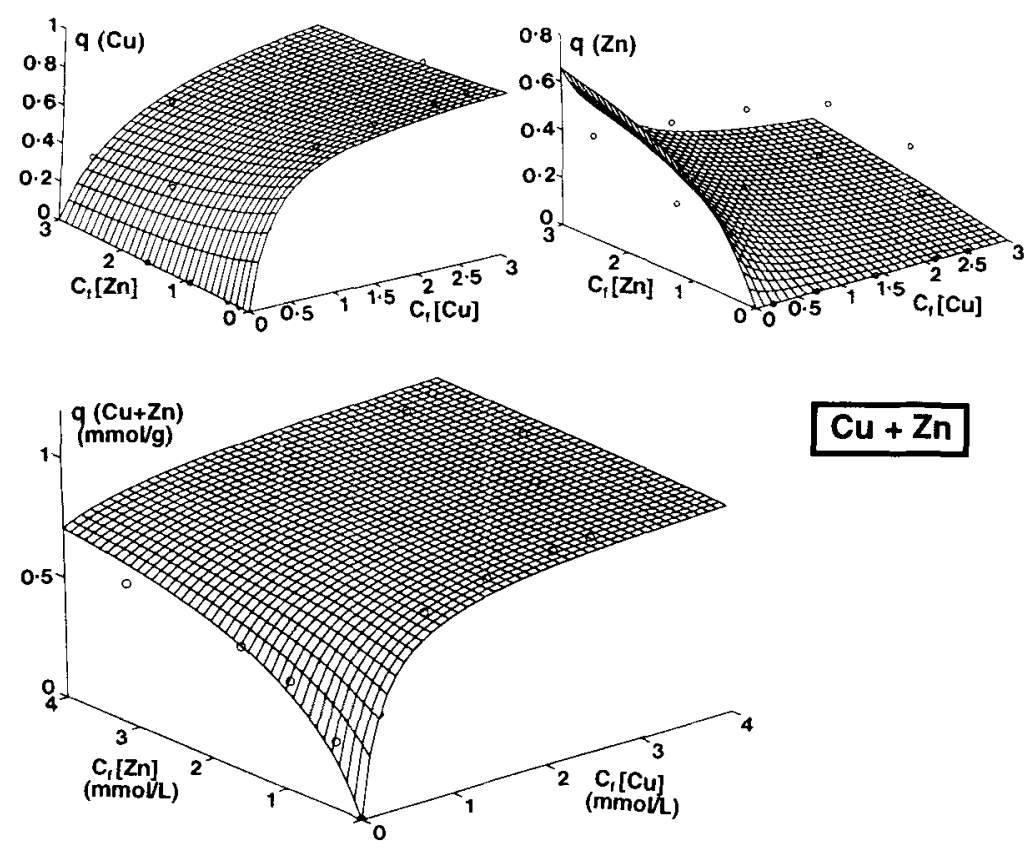

$\mathrm{Cu}+\mathrm{Zn}$

(c)

Figure 3. (Continued).

segment of Fig. 4b), whereby increasing $C_{f}[\mathrm{Zn}]$ only augmented the total metal uptake by a minute amount $\left(q_{\text {total }}\right.$ increased from 0.84 to $0.85 \mathrm{mmol} / \mathrm{g}$ for the range of $C_{f}[\mathrm{Zn}]$ from 0 to $2.5 \mathrm{mmol} / \mathrm{L}$ ), since the total metal concentrations at these conditions were high enough to load the biosorbent near its limiting uptake capacity. Since Model 1 predicted the $q_{\max }$ of this system to be $0.92 \mathrm{mmol} / \mathrm{g}$, the biosorbent still had some reserve metal uptake ability, however, only when subjected to higher total metal concentrations.

When the residual concentrations of copper and zinc were the same (e.g., $0.5 \mathrm{mmol} / \mathrm{L}$ each or $2.5 \mathrm{mmol} / \mathrm{L}$ each), about $83 \%$ of the total metal uptake was due to copper uptake. At $C_{f}[\mathrm{Cu}]=0.5$ and $C_{f}[\mathrm{Zn}]=2.5 \mathrm{mmol} / \mathrm{L}$, the uptake of each metal was $0.38 \mathrm{mmol} / \mathrm{g}$. Thus, the equilibrium concentration of zinc would have to be five times greater than that of copper to obtain the same proportion of uptake for each metal. Similar to the case of the $\mathrm{Cu}-\mathrm{Cd}$ system, at high concentrations of copper $(2.5 \mathrm{mmol} / \mathrm{L})$, the inhibition of $\mathrm{Cu}$ sorption was being compensated by the $\mathrm{Zn}$ uptake with the total uptake remaining relatively constant.

In general, the biosorbent exhibited a net preference for the $\mathrm{Cu}$ ion over $\mathrm{Zn}$. However, when comparing $(\mathrm{Cu}-\mathrm{Cd})$ and $(\mathrm{Cu}-\mathrm{Zn})$ systems, the uptake of $\mathrm{Cu}$ is more susceptible to interference from $\mathrm{Cd}$ than from $\mathrm{Zn}$.

\section{Cd-Zn System}

The total $q_{\max }$ of this system is the lowest among the three systems examined (see Fig. 4c). Again, the same phenomena are being described by Model 1: each metal inhibits the sorption of the other and, at low total residual metal concentrations, the total metal sorption uptake increased. At higher total metal concentrations, the total metal sorption uptake remained relatively constant. At $C_{f}[\mathrm{Cd}]=2.5$ $\mathrm{mmol} / \mathrm{L}$ (last segment of Fig. 4c), Zn must have been progressively replacing $\mathrm{Cd}$ on the same sorption sites since the total metal uptake remained unchanged.

Cadmium uptake accounted for $75 \%$ of the total metal uptake when the final concentrations of both metals were similar. The residual concentration of zinc would have to be three times that of cadmium to produce the same amount of uptake of each metal. For example, at $C_{f}[\mathrm{Cd}]=0.5$ and $C_{f}[\mathrm{Zn}]=1.5 \mathrm{mmol} / \mathrm{L}$, each individual metal uptake would account for $50 \%$ of the total metal uptake. At higher residual concentrations of $\mathrm{Cd}(2.5 \mathrm{mmol} / \mathrm{L})$, the metal uptakes of $\mathrm{Cd}$ and $\mathrm{Zn}$ remained relatively constant with respect to the case when there was an absence of zinc.

A definite preference of the FCAN2 biosorbent for sorbing $\mathrm{Cd}$ over $\mathrm{Zn}$ could be observed over the equilibrium concentration range examined.

The metal preference exhibited by FCAN2 can be exemplified by Figures 5 and 6 . For the following discussion, two concentrations have been arbitrarily chosen to represent "low" $(0.5 \mathrm{mmol} / \mathrm{L})$ and "high" $(2.5 \mathrm{mmol} / \mathrm{L})$ residual concentrations, respectively.

Figure 5a demonstrates that, at both low and high residual concentrations of zinc, its uptake would become less than $80 \%$ of the initial value when the concentration of $\mathrm{Cu}$ or Cd exceeded $0.3 \mathrm{mmol} / \mathrm{L}$. The apparent "affinity" exhibited by FCAN2 for Zn decreased drastically when $\mathrm{Cu}$ or $\mathrm{Cd}$ were present: Langmuir $\mathbf{b}$ values decreased from 2.3 to below 0.6 when the equilibrium concentration of cocations exceeded $0.5 \mathrm{mmol} / \mathrm{L}$ (Figure $6 \mathrm{a}$ ).

The uptake of $\mathrm{Cd}$ was much more sensitive to the presence of $\mathrm{Cu}$ than to that of $\mathrm{Zn}$. Langmuir $\mathbf{b}$ parameters for $\mathrm{Cd}$ decreased from 5.0 to below 1.0 in the presence of $\mathrm{Cu}$ while they did not reach below 1.0 when $\mathrm{Zn}$ was present at high concentrations (Fig. 6b). At high residual concentrations of 

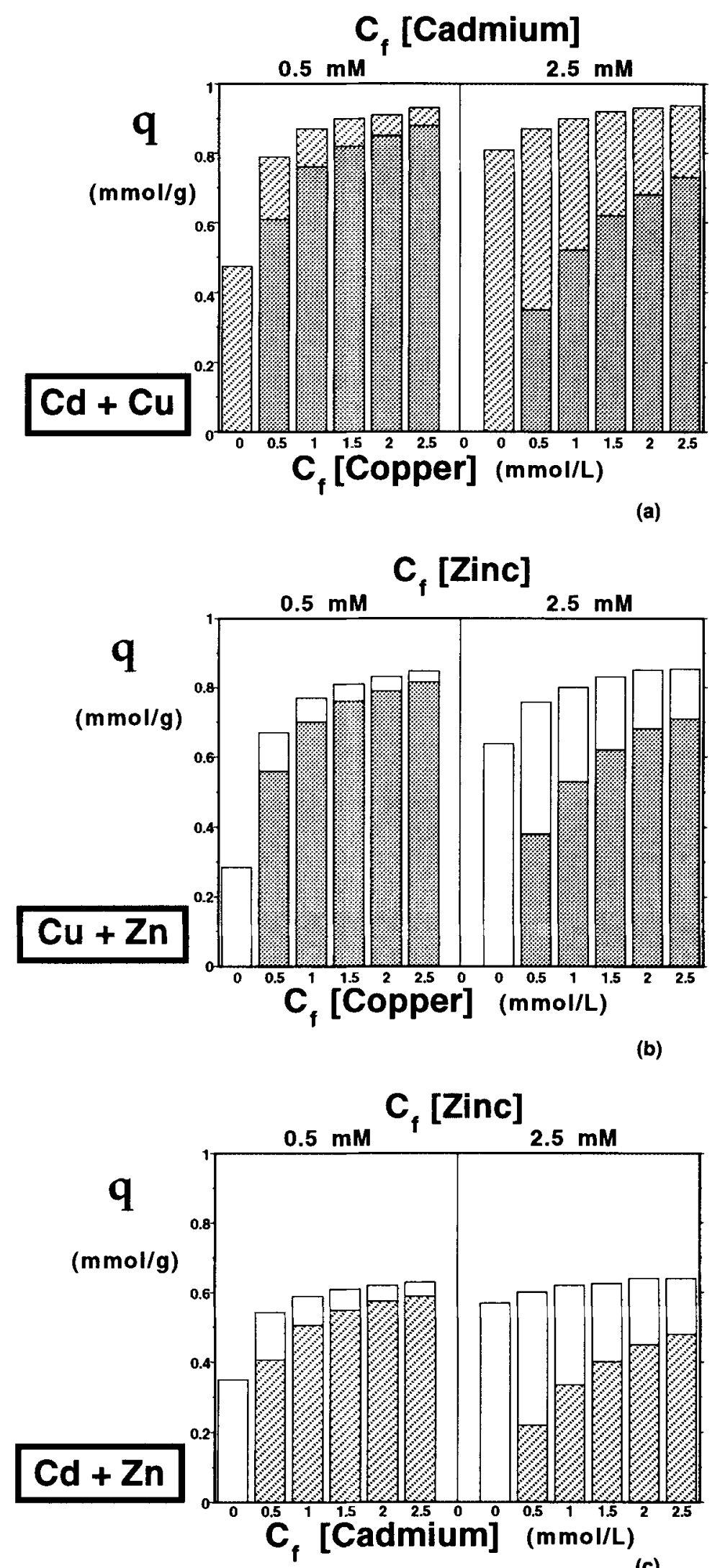

(a)

(b)
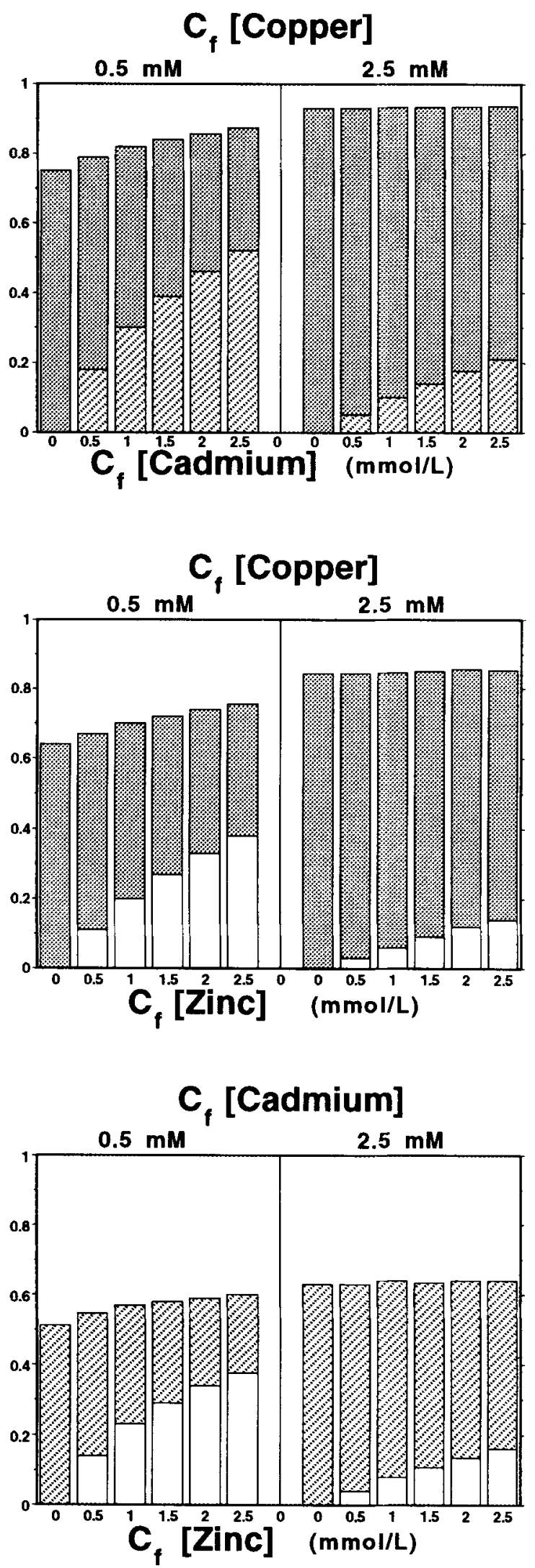

(c)

Figure 4. "Iso-concentration" cuts of the two-metal sorption isotherm surfaces for FCAN2 biosorbent: sorption uptakes from the two-metal solution vs. the equilibrium concentration of one metal, while the equilibrium concentration of the other metal is held as a constant parameter. (a) Additive Cd ( 2 ) and $\mathrm{Cu}(\boldsymbol{\square})$ metal uptakes as a function of the final $\mathrm{Cu}$ concentration and the final $\mathrm{Cd}$ concentration, respectively. (b) Additive $\mathrm{Cu}(\boldsymbol{\square})$ and $\mathrm{Zn}(\square)$ metal uptakes as a function of the final $\mathrm{Cu}$ concentration and the final $\mathrm{Zn}$ concentration, respectively. (c) Additive $\mathrm{Cd}(\mathrm{Z})$ and $\mathrm{Zn}(\square)$ metal uptakes as a function of the final $\mathrm{Cd}$ concentration and the final $\mathrm{Zn}$ concentration, respectively. 


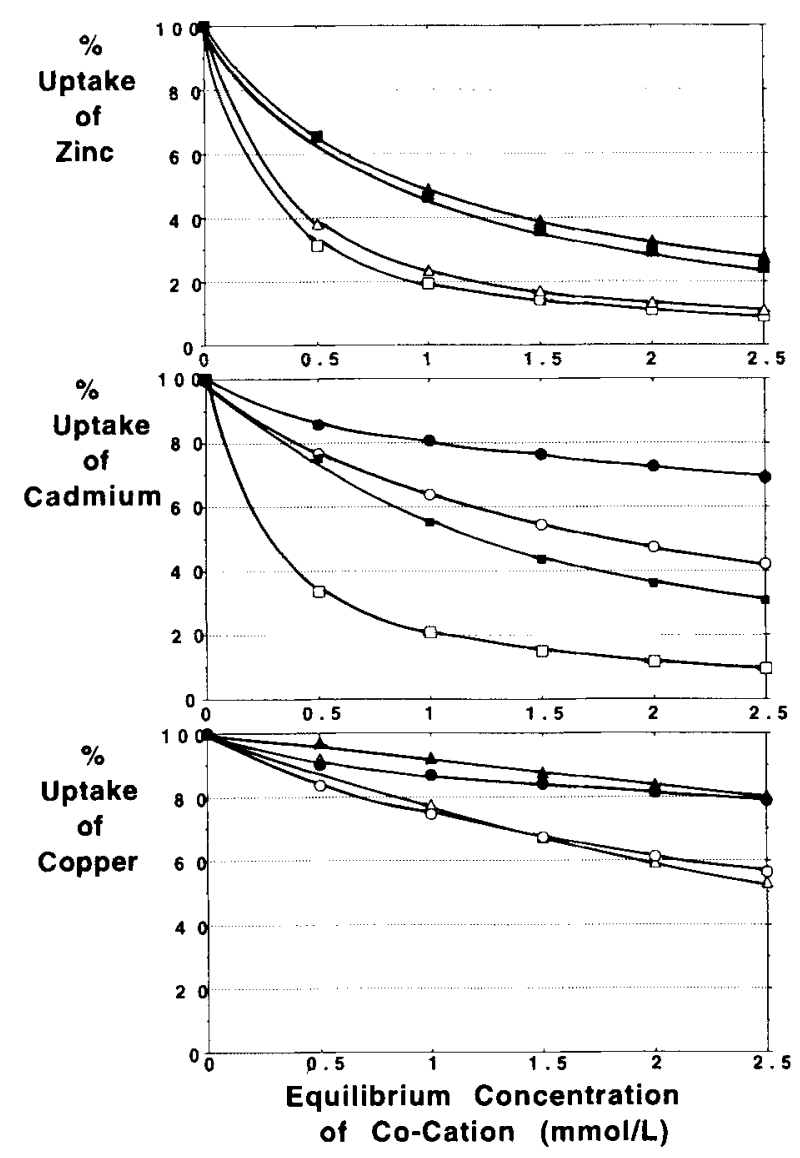

Figure 5. Effects of cocation $\left(\mathrm{M}_{2}\right)$ on the uptake of the primary metal $\left(\mathrm{M}_{1}\right)$ by FCAN2 biosorbent. Curves: $(\square) C_{f}\left[\mathrm{M}_{1}\right]=0.5 \mathrm{mmol} / \mathrm{L}, \mathrm{M}_{2}$ : copper; $(\mathbf{Q}) C_{f}\left[\mathrm{M}_{1}\right]=2.5 \mathrm{mmol} / \mathrm{L}, \mathrm{M}_{2}:$ copper; $(\triangle) C_{f}\left[\mathrm{M}_{1}\right]=0.5 \mathrm{mmol} /$ $\mathrm{L}, \mathrm{M}_{2}$ : cadmium; $(\Delta) C_{f}\left[\mathrm{M}_{1}\right]=2.5 \mathrm{mmol} / \mathrm{L}, \mathrm{M}_{2}:$ cadmium; $(O) C_{f}\left[\mathrm{M}_{1}\right]$ $=0.5 \mathrm{mmol} / \mathrm{L}, \mathrm{M}_{2}:$ zinc; $\left(C_{f}\left[\mathrm{M}_{\mathrm{l}}\right]=2.5 \mathrm{mmol} / \mathrm{L}, \mathrm{M}_{2}:\right.$ zinc.

Cd, an approximately $20 \%$ decrease in the Cd equilibrium uptake resulted already at $0.5 \mathrm{mmol} \mathrm{Cu} / \mathrm{L}$ at equilibrium, whereby the same decrease in the Cd uptake did not occur until approximately $1.2 \mathrm{mmol} / \mathrm{L}$ of residual $\mathrm{Zn}$ in the solution (Fig. 5b).

The presence of $\mathrm{Cd}$ and $\mathrm{Zn}$ alter the "apparent affinity" of FCAN2 for $\mathrm{Cu}$ as shown in Figure 6c. At low residual concentrations of $\mathrm{Cu}$, a decrease in excess of $20 \%$ could be noted in the $\mathrm{Cu}$ sorption uptake at residual concentrations of the other metals of $1 \mathrm{mmol} / \mathrm{L}$. At a high residual concentration of $\mathrm{Cu}$, the same amount of decrease would only occur when the residual concentrations of the other metals exceeded $2.5 \mathrm{mmol} / \mathrm{L}$ (Fig. $5 \mathrm{c}$ ).

The value of apparent dissociation constant $K$ for a metal in one two-metal system is different from that in another two-metal system. Moreover, the maximum uptake capacity of FCAN2 biosorbent is different depending on which two metals are in solution $\left(q_{\max }\right.$ values for each of the two-metal systems are not the same). This might indicate the possibility of at least some portion of different adsorption sites binding different metal ions. Future work should include performing experiments to investigate these phenomena, which are apparently related to the mechanisms of

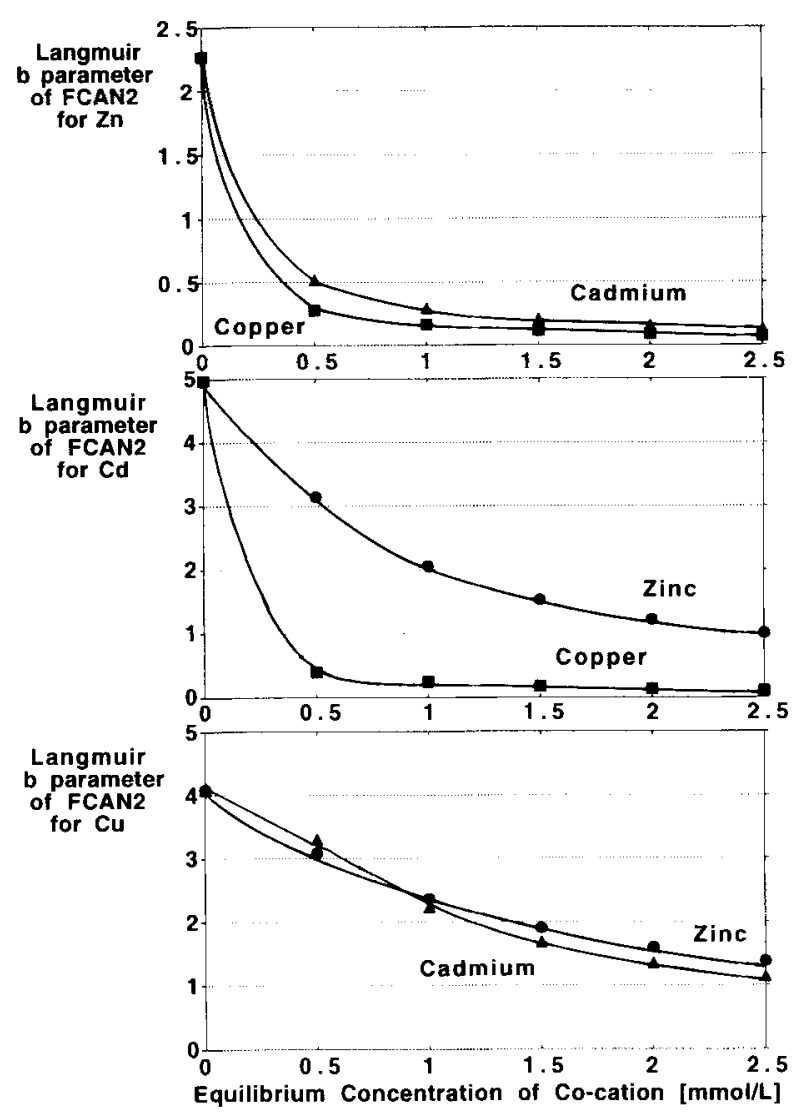

Figure 6. Effects of co-cations on the Langmuir $b$ value of FCAN2 biosorbent for the primary metal.

metal biosorption. However, one has to realize the complexity of investigating the mechanisms of biosorption which could be any or a combination of these processes: complexation, coordination, chelation, ion exchange, physical adsorption, or inorganic microprecipitation of metals.

From the information on the three two-metal systems, some predictions can be made as to the possible behavior of a three-metal system. In a three-metal system comprised of $\mathrm{Cu}, \mathrm{Cd}$, and $\mathrm{Zn}$, for the same equilibrium concentrations of each of the metals (regardless of "low" or "high" residual concentrations), the following would be the predicted range of percent metal uptake by FCAN2 biosorbent: copper, 55\% to $71 \%$; cadmium, $20 \%$ to $34 \%$; and zinc, $8 \%$ to $14 \%$. For the same amount of each metal to be sequestered by the biosorbent, a possible ratio of the residual concentrations

$$
C_{f}[\mathrm{Zn}]: C_{f}[\mathrm{Cd}]: C_{f}[\mathrm{Cu}] \text { is } 5: 3.5: 1 \text {. }
$$

These predictions need to be verified in a next set of experimental 3-metal equilibrium (bio)sorption studies.

It would be of interest to examine if the Langmuir-like multicomponent isotherm models could represent the equilibria data of the three-metal system in a reasonable manner. Otherwise, other models would have to be sought to describe the three-metal (bio)sorption equilibria and to provide a desirable tool for predicting the respective metal uptakes. 
Earlier work with the new FCAN biosorbent ${ }^{5}$ did not employ models to describe the 3-D sorption isotherm surfaces and, consequently, the results of two-metal studies in that work could not be extrapolated and only qualitative comparison for the biosorption of two metals could be made (i.e., no predictive conclusions could be drawn). Further inaccuracies stemmed from the fact that the crude fresh FCAN biosorbent used leached alginate during the metal biosorption ${ }^{4}$ and corrections were introduced in the calculation of metal uptakes to account for the metal precipitated outside in the solution. The results of that work used "Delta Graph" software to plot the 3-D sorption isotherm surfaces. Tedious and error-prone manual interpolations had to be performed prior to data input when using this system. FCAN2 used in the present experiments was preconditioned so that no release of its component materials or precipitation of metals occurred and "pure" sorption could be studied. The application of MATLAB 4.0 enabled the current work to produce results which can serve as a more reliable and accurate quantitative basis for judging the performance of the new biosorbent material. At the same time, a suitable methodology is outlined here which represents another step in standardizing the evaluation of biosorption performance.

The contribution of the FCAR Quebec Scholarship to K. H. Chong is gratefully acknowledged.

\section{References}

1. Bailey, J. E., Ollis, D. F. 1986. pp. 120-129. Biochemical engineering fundamentals. 2nd edition. McGraw-Hill, New York.

2. Crist, R. H., Martin, J. R., Carr, D., Watson, J. R., Clarke, H. J., Crist, D. R. 1994. Interaction of metals and protons with algae. 4. Ion exchange vs adsorption models and reassessment of Scatchard plots; ion exchange rates and equilibria compared with calcium alginate. Environ. Sci. Technol. 28: 1859-1866.

3. Crittenden, J. C., Weber, W. J. 1978. Model for design of multicomponent adsorption systems. J. Environ. Eng. 104: 1175-1195.

4. de Carvalho, R. P., Chong, K.-H., Volesky, B. 1994. Effects of leached alginate on metal biosorption. Biotechnol. Lett. 46: 875-880.

5. de Carvalho, R. P., Chong, K.-H., Volesky, B. 1995. Evaluation of the $\mathrm{Cd}, \mathrm{Cu}$ and $\mathrm{Zn}$ biosorption in two-metal systems using algal biosorbent. Biotechnol. Prog. 11: pp 39-44.

6. Ferguson, J., Bubela, B. 1974. The concentration of Copper (II), Lead (II), and Zinc (II) from aqueous solutions by particulate algal matter. Chem. Geol. 13: 163-186.
7. Foster, P. 1976. Contamination and concentration factors of heavy metals in brown algae. Environ. Pollut. 10: 45-53.

8. Fourest, E., Roux, J.-C. 1994. Improvement of heavy metal biosorption by mycelial dead biomass (Rhizopus arrhizus, Mucor miehei and Penicillium chrysogenum): $\mathrm{pH}$ control and cationic activation. FEMS Microbiol. Rev. 14: 325-332.

9. Garnham, G. W., Codd, G. A., Gadd, G. M. 1992. Kinetics of uptake and intracellular location of cobalt, manganese and zinc in the estuarine green alga Chlorella salina. Appl. Microbiol. Biotechnol. 37: $270-276$.

10. Gee, A. R., Dudeney, A. W. L. 1988. Adsorption and crystallization of gold at biological surfaces, pp. 437-451. In: P. R. Norris and D. P. Kelly (eds.), BioHydroMetallurgy: Proceedings of the International Symposium on Science Technology Letters. Kew Surrey, UK.

11. Greene, B., McPherson, R. A., Darnall, D. W. 1987. Algal sorbents for selective metal ion recovery, p. 315. In: J. Patterson and R. Pasino (eds.), Metals speciation, separation and recovery. Lewis, Chelsea, MI.

12. Holan, Z. R., Volesky, B. 1994. Biosorption of lead and nickel by seaweed materials. Biotechnol. Bioeng. 43: 1001-1009.

13. Holan, Z. R., Volesky, B., Prasetyo, I. 1993. Biosorption of cadmium by biomass of marine algae. Biotechnol. Bioeng. 41: 819-825

14. Kuyucak, N., Volesky, B. 1989. Accumulation of gold by algal biosorbent. Biorecovery 1: 189-204.

15. Liapis, A. I., Rippin, D. W. T. 1977. A general model for the simulation of multi-component adsorption from a finite bath. Chem. Eng. Sci. 32: 619-627.

16. Moore, J. W., Ramamoorthy, S. 1984 pp. 28-57, 77-99, 182-204. In: Heavy metals in natural waters. Springer Verlag, New York.

17. Niu, H., Xu, X. S., Wang, J. H., Volesky, B. 1993. Removal of lead from aqueous solutions by Penicillium biomass. Biotechnol. Bioeng. 42: 785-787.

18. Prasetyo, I. 1992. Removal of toxic metals from aqueous solutions by biosorption, M.Eng. thesis, McGill University, Montreal, Quebec, Canada.

19. Townsley, C. C., Ross, I. S., Atkins, A. S. 1986. Biorecovery of metallic residues from various industrial effluents using filamentous fungi, pp. 279-289. In: R. W. Lawrence, R. M. R. Branion, and H. G. Ebner (eds.), Fundamental and applied biohydrometallurgy. Elsevier, Amsterdam.

20. Trujillo, E. M., Jeffers, T. H., Ferguson, C., Stevenson, H. Q 1991. Mathematically modelling the removal of heavy metals from wastewater using immobilized biomass. Env. Sci. Technol. 25 1559-1565.

21. Tsezos, M. 1986. Adsorption by microbial biomass as a process for removal of ions from process or waste solutions, pp. 201-226. In: H. H. Eccles and S. Hunt (eds.), Immobilisation of ions by biosorption. Ellis Horwood, Ltd., Chichester, West Sussex, UK.

22. Volesky, B. 1990. Removal and recovery of heavy metals by biosorption, pp. 7-44. In: B. Volesky (ed.), Biosorption of heavy metals. CRC Press, Boca Raton, FL. 